\title{
Acculturation strategies of Chinese students in Indonesia
}

\section{Chen Yanrenjing1, Pande Made Kutanegara ${ }^{2 *}$}

\author{
1 Streetcorner Ecommerce Limited, Shenzhen, China. \\ 2 Department of Anthropology, Faculty of Cultural Science, Universitas Gadjah Mada Yogyakarta, \\ Indonesia.
}

*Corresponding Author: pkutanegara@yahoo.com

\begin{tabular}{|c|c|}
\hline ARTICLE INFO & ABSTRACT \\
\hline $\begin{array}{l}\text { Keywords: } \\
\text { Acculturation; Chinese } \\
\text { students; acculturation } \\
\text { difficulties; acculturation } \\
\text { strategies; Yogyakarta. }\end{array}$ & $\begin{array}{l}\text { This article tries to analyze the acculturation process and } \\
\text { acculturation strategies of Chinese students in Indonesia, particular } \\
\text { in Yogyakarta. In recent years, the number of Chinese students } \\
\text { studying abroad has increased rapidly, and Indonesia has also become } \\
\text { one of the destinations. In response to the call of the "One Belt, One } \\
\text { Road" }\end{array}$ \\
\hline How to cite: & $\begin{array}{l}\text { Road policy, Chinese universitles have establishea Inaonesian } \\
\text { language majors. More and more Chinese students come to Indonesia }\end{array}$ \\
\hline Yanrejing, C., & as exchange students, and at the same time are experiencing the \\
\hline Kutanegara, P.M. (2021). & process of acculturation. This research uses Yogyakarta as a research \\
\hline Acculturation strategies of & base and aims to propose strategies for the acculturation of Chinese \\
\hline Chinese students in & students in Yogyakarta. The research uses ethnographic methods; \\
\hline Indonesia. ETNOSIA: & literature reviews, participant observation, and structured interviews \\
\hline Jurnal Etnografi & for data collection. The study found that in the early period, Chinese \\
\hline Indonesia. 6(2), 170 - 183. & $\begin{array}{l}\text { students had quite a lot of difficulty in adapting and acculturating } \\
\text { with local people and culture. In the process of adaptation, Chinese }\end{array}$ \\
\hline DOI: & students should improve the initiative of acculturation, cultivate new \\
\hline 10.31947/etnosia.v6i2.18092 & ideas and value systems, and learn to enjoy Indonesian customs. \\
\hline
\end{tabular}

\section{Introduction}

With the development of China's One Belt One Road policy, economic and cultural exchanges between China and Southeast Asian countries have become closer and closer. The opening of Indonesian subjects by universities and the proximity of geography have resulted in the continued increase in the number of Chinese tourists and international students in Indonesia. For Indonesian language learners, whether they are active or passive, they are faced with the " $3+1$ " or "2+2" learning model ${ }^{1}$ set by colleges and universities. In other words, as long as you choose the major of Indonesian, you have the option of staying in the target country for at least one year. Studying abroad is far from being as glamorous as it sounds, let alone in Indonesia, which lacks understanding. 1 The "3+1" model means that after choosing the language major, you will study domestically for three years and
study in the target country for one year. Similarly, the " $2+2 "$ is also so. 
For most people, there is still an indelible "anti-China" stereotype. So after a short period of "freshness", Chinese students seem to be in trouble.

According to rough estimates, there are about 200 Chinese students from various regions and schools in Yogyakarta each year, mainly in GuangXi University for Nationalities, Yunnan Minzu University and Guangdong University of Foreign Studies, Tianjin Foreign Studies University, QuJing Normal University, Beijing Foreign Studies University, etc. UGM, UAD, UNM, UNY, and other schools in Yogyakarta are all universities that have cooperation with Chinese institutions. Chinese students who wish to exchange are faced with the choice of staying for two or one year in the undergraduate era, although they come from different regions in China, there will be a little difference in culture, but I think the commonality of Chinese students is quite big. In terms of religion and language, except for Muslim students, almost all Chinese students are not religious. And just like in most parts of China, when you are exposed to an unfamiliar environment and still have to communicate with people of the same race, Chinese students will choose to communicate in Mandarin. What I mean is that even if a large number of Chinese students from different regions of China with their own different cultures come to Yogyakarta every year, the difficulties they face are still consistent. What causes difficulties is not the different cultural characteristics carried in the country of origin, but the different concepts and specific emotions formed and carried after coming to Yogyakarta. More specifically, there is no evidence to prove that which cultural gene from which region of China is better for acculturation in Yogyakarta.

From the perspective of a novice, the first thing that causes uneasiness is the unfamiliar environment and strange people or things, which will cause a series of negative emotions such as fear, anxiety, and homesickness. Different languages may make this situation worse. When Chinese international students eat unaccustomed meals, speak unfluent languages, and experience a completely unfamiliar cultural system, the initial "freshness" will be concealed by some subsequent problems that have to be faced. I remember the first night I came to Yogyakarta, staying in the school hotel, because it was too hot, I casually wore a pair of shorts and went downstairs to the nearby supermarket to buy things. Although I heard some advice from teachers or seniors before going abroad, saying that there are many Muslims in Indonesia, don't dress too revealing, and think I'm mentally prepared, but when I actually appeared in the store, I faced the eyes of the public. At that time, I realized that I was not ready at all. What was it like at that time? I think there was curiosity in those eyes, they might be guessing that I am a foreigner; there were doubts, they felt that I should not appear in the sight of the public in such short pants; there were contempt, that I am not reserved enough, and not dignified enough. When I got off the plane, I saw so many Muslim women wearing hijabs and long skirts, which did not make me feel cultural conflict; eating fried chicken and juice during meals did not make me surprised or uncomfortable. But the eyes of public in that night made me feel for the first time that I really left China and entered a completely unfamiliar place. 
Having an extroverted personality may be more conducive to dealing with these negative emotions. It just so happens that I am such a person. I liked playing with Indonesians very much. Of course, they also took care of me in the process of getting along. For example, they helped me prepare chopsticks, went to eat in restaurants where I didn't need to take off my shoes, and took me to places that I thought were cleaner. I am enjoying the benefits brought by others accommodating me, so when I saw that some of my classmates were too "individualized" and didn't go out to play with Indonesians very much, and complaind to me every day that they can't stand Indonesia and wanted to go back to China, I were not in the mood to take care of their feelings, let alone reflect on the deep meaning behind these phenomena.

The turning point occurred after I came to Indonesia to study as a graduate student. Before graduating from my undergraduate degree, I was ready to study at UGM. Because I like Yogyakarta too much, I didn't consider UI. Even if I had to wait for a year, I chose UGM. After leaving the group life, I really started to live independently and study independently, which made me feel that the experience of graduate school is very different from the experience of 10 months in Yogyakarta for the first time. Maybe because I didn't have a deeper understanding and exploration at the time, and I was always taken care of by others, I thought everything was fine, but when I really penetrated into this environment, the sense of gap began to make me think: What is the real "acculturation"? Some questions began to emerge in my mind: Why do Chinese students feel unable to establish a deep friendship with Indonesians? Why do I, who have strong academic ability and have good grades in undergraduate studies, feel confused and helpless in graduate courses? Why do Indonesians and I have two completely different ideas about the same thing? Is my "feel" right? With these questions, I became interested in the acculturation of Chinese students in Yogyakarta.

Arnold (1882) once said: "Culture... Seeks to do away with classes; to make the best that has been thought and known in the world current everywhere; to make all men live in an atmosphere of sweetness and light..." Culture was born of mankind, and the civilization of the human world is embodied in the fusion of different cultures. For thousands of years, we humans have been born, reproduced, migrated, and settled. Different times and geographical environments have bred different civilizations. After human beings enter the era of great civilization, when we face the conflict between identity and collective identity, cross-cultural misunderstandings will be more likely to occur, because culture is a way of life that individuals inherit, share and learn in society because of their membership in a social group. In a material sense, culture constitutes the background of personal understanding and pursuit of conflict (Avruch, 2002). Some people believe that cross-cultural misunderstandings are caused by negative stereotypes (Fridgen, 1991; Reisinger \& Tuner, 2003; Triandis, 1972), because culture shock is considered a negative state (Ward, 2001), but no matter what it is a positive or a negative cultural shock, it is possible to provide a huge opportunity for the cultural learning and personal growth of the affected person. Dabrowski (1964) called this opportunity "positive disintegration", that is, the self has found another meaningful self, and this disintegration can effectively act on the self and others. 
The process of acculturation will first experience culture shock. Culture shock is defined as the process of initial adjustment to an unfamiliar environment (Pedersen, 1995). This term is widely used in tourism literature to explain the various difficulties encountered by international tourists to another country. Although Hottola (2004) criticized the excessive attention to culture shock in cross-cultural tourism, he believed that people who experience cultural shock are themselves participants in globalization, but I believes that how to deal with or solve cultural shock is more important than the critical point, because when people are inevitably exposed to cultural shock, this is a situation where real world opportunities and challenges coexist, and what we have to do is to make distinctive cultural characteristics persist (Moufakkir, 2013).

The earliest definition of acculturation comes from Redfield, Linton, and Herskovits (1936):

Acculturation refers to the phenomenon caused when groups of individuals with different cultural backgrounds continue to make first-hand contact, and the primitive cultural patterns of one or both of these two groups have subsequently changed.

Acculturation takes place in every corner of the world. It is not only related to the physical and mental health of the adaptor, but more importantly, the symbiotic social emotions generated in the interaction. This interactive new relationship includes but is not limited to emotional aspects.

Today, we are faced with the challenges of global life. Even if we strive to develop a global community, we have to experience and witness fragmentation and isolation. What needs to be understood in wars in different regions of the world today is not the black and white truth, but the struggle to understand the conflicts between different cultures and values (Cupsa, 2018). It is difficult to say which country in the world today can completely reject the influence of globalization. This is an economic trend as well as a cultural trend.

The article tries to discuss the acculturation process and strategy carried out by Chinese students in Yogyakarta. Acculturation is not an easy task, but a long process, which has nurtured acculturation strategies from various students.

\section{Method}

This study was conducted in Indonesia, particular in Yogyakarta. The study used ethnographic methods. Research collects data through participant observation, structured interviews and literature review. The study was conducted on 10 informants, including 3 male and 7 female informants. Among them, 7 of them have graduated from undergraduates, 2 are in graduate studies, and 1 are in doctoral studies. They lived in Yogyakarta for a minimum of 10 months and a maximum of 4 years. The informant is composed of my classmates and friends, and some people introduced by friends. They have a religious distinction, namely Muslims and non-Muslims. At the same time, using academic performance as a reference, some are positive examples and some are negative examples. Moreover, they also have different preferences for Indonesia. Now, some of 
them are already working and some are still going to school for further study. Due to the difficulties caused by the epidemic, except for two graduate students like me who are studying in Yogyakarta, the other 8 informants can only be interviewed by telephone.

\section{Result and discussion}

\section{- Acculturation difficulties: rejection of initiative, the collision of ideas and external factors}

From the perspective of acculturation initiative, acculturation groups are usually divided into two categories: active acculturation groups and passive acculturation groups. Actively acculturated groups include: groups that are subjectively willing to adapt to culture, and groups with outgoing personalities. The negatively acculturated group is the opposite of the above two classifications. Regardless of whether it is a positive acculturation group or a passive acculturation group, they first face the "social dominance model", that is, the two groups have similar development levels in all aspects, which can better promote acculturation. And the social status of the two societies are too different, which will make adaptors have an attitude of "looking up" or "looking down" psychologically, and lose the ability to balance themselves or adapt to the social status of the region. To put it simply, in addition to their own personality factors that are difficult to change, the higher "social status" held by Chinese international students will reduce their interest in acculturation.

Religious issues are another problem that Chinese international students find difficult to overcome in the field of ideology. As the world sees, China is one of the few socialist countries in the world. The party governed by the Communist Party is an atheist party. Atheism is included in China's basic education system. For Chinese students who have been influenced by materialism since childhood, they do not understand some religious doctrines and religious codes of conduct. Secondly, for the Chinese, Islam is a special existence compared to other religions. First of all, Chinese Muslims have a relatively poor sense of recognition because of the "independence uprisings" initiated several times, and because of their gathering and religious unity, they may be seen as an obstacle to national unity. In the end, there may be some differences in world outlook and living habits due to religious reasons. For example, Muslims do not eat pork, and even Muslims' worship will be regarded as a waste of time by Chinese students. Regarding negative impressions of religion, my informants said this:

But in fact, it is this religion, especially Islam, which affects me most. In essence, I think this religion is not problematic. It is the behavior of believers. The actual operation is deviated from the theory ... They are not very good to fulfill this religious obligation and responsibility. (Ayong)

The difficulty caused by the ideological field is the Indonesian "santai"2. Generally speaking, this kind of "santai" will leave the impression that "Indonesians are lazy" to the Chinese who pursue efficiency. Because in terms of work, it seems difficult for Indonesians to achieve the expected results within the expected time. And in life, the most obvious behavior is being late. This "be late" is not a few minutes or ten minutes, it

\footnotetext{
2 Santai, Indonesian language: free from tension; in a state of freedom and leisure.
} 
may be an hour, but they obviously have more explanatory experience for being late: heavy traffic, oversleeping, take a shower first. This kind of "santai" left a negative impression on Chinese students:

I think Indonesians are more santai, and I'm a more nervous person who doesn't like procrastination. I think in terms of religion, for example, those go jek drivers, they originally rely on this to make money, they should have professional ethics, instead of telling me at any time to let me wait a little longer, buy a pack of cigarettes or worship first. I think I paid you money and you should give me the corresponding service. Moreover, Indonesians don't want to solve the problem the first time when they are in trouble, but berdoa3 first. I don't think I can understand it. ( Novi)

In terms of external factors, Chinese students must first face cultural shocks from diet, which mainly include taste, eating habits and health standards. For Chinese students, quickly adapting to fried foods may be a difficult attempt. The fried chicken, fried tofu, fried fish, fried prawn crackers, and fried rice with similar taste everywhere in Yogyakarta will become the helpless choice for Chinese students in the early stage. And because of differences in climate or different eating habits since childhood, Indonesians seem to have a hard time understanding why Chinese get heaty ${ }^{4}$. In terms of eating habits, I found that Indonesians don't care much about the degree of hot or cold food, so you can find that in many non-high-end Padang restaurants or similar cafeterias, except for the hot rice, most dishes and even soups are cold. But in fact, many Chinese people think that cold dishes are not tasty and can even cause gastrointestinal problems.

The health standards of food are also worrying. Fresh ingredients and clean practices may be the common pursuit of diners, but at this point, some foods in Yogyakarta often fail to meet such expectations. For example, There may be feathers left on the "sate" that is almost everywhere, and the chef almost does not wear masks or gloves and directly cook. In this regard, my informant Xiaohao also expressed some concerns:

Secondly, the sanitation environment is too bad, food sanitation and environmental sanitation are not very good (Xiaohao).

Climate issues also make acculturation difficult. Yogyakarta belongs to a tropical monsoon climate, with an average annual temperature of $26^{\circ} \mathrm{C}-27^{\circ} \mathrm{C}$. The humid heat caused by the tropical monsoon climate first brought mosquito troubles. I still remember the nightmare of fighting ants when I was in Yogyakarta in 2016. Why is it a "nightmare"? Because I am not afraid of ants, but piles of ants can make people feel sick. Many Chinese people are "fear of ants" because they feel sick and unclean, especially if ants are found in hotels, rooms or even beds, which will become more frightening things.

The negative expectation is also caused by the Indonesian habit of sitting on the floor. At the food stalls on the street, people are used to spread a mat and sit on the spot. Food

\footnotetext{
3 Berdoa, Indonesian language: prey.

4 "Get heaty " can be explained from the theory of Chinese medicine and falls into the category of Chinese medicine fever. Traditional Chinese medicine believes that if the body's yin and yang are unbalanced, the internal fire will overheat. Specific symptoms include eye irritation, oral erosion, yellow urine, toothache, sore throat, etc.
} 
and drink are placed on the mat. The difficulty in adapting to the Chinese students may come from the customary convention of having to put food on the table in eating habits.

\section{- Improve acculturation initiative}

The so-called "social status gap" is a proper term constructed from the psychological gap. Simply speaking, it means "ours are all good, and yours are not good." It is undeniable that I have also experienced the process of "social status gap". This "gap" includes the belief that the living environment is too simple, the lack of rigid facilities, the poor sanitation environment, and the food health defects. And some adults cannot count as elementary school mathematics. No matter what they do, they just do it too casually.

This kind of superiority is produced by the combination of internal functions and external factors. In the face of this gap, I have an interesting "equal substitution" suggestion, that is, in the same aspect, when people have a psychological gap, to make up for the shortcomings by using other better performance. For example, when you feel that the cleaning service has been waiting too long, but you still should not forget the satisfactory quality and pleasant attitude of the cleaning service. The significance of equivalent substitution is that it enables us not only to see one aspect that we are not satisfied with, but also to discover from other aspects that Indonesia has advantages that China does not have, in order to balance the stereotype of "gap". It is true that not all aspects can be replaced by the same amount, but the point is that when you have a psychological gap, you should find a fulcrum to prevent yourself from falling into the predicament of blind superiority.

From the subjective initiative of Marx's theory, extroversion can be cultivated. First of all, we must start with a change of thinking. Trying is the source of all opportunities. In such a diverse and inclusive cultural environment, I think I can bravely embrace the mentality of "I am ignorant, I can be forgiven" to break some of the confinement of thinking. More utilitarianly, when we have a personality that is conducive to our own acculturation, when we gradually begin to establish close relationships with locals and truly participate in it, we can build a wealth of social capital and use these social capital to solve the problem that cannot be solved by oneself and others. What I mean is not that introversion is bad, but that we are already in the environment, how to make ourselves happy, and acculturate efficiently is necessary. If you don't like to communicate with people, please don't refuse others to approach you actively. Even in some daily oral communication, we can also learn some more authentic language usage.

\section{- Cultivate a new system of ideas and values}

How to deal with religious differences is a difficult process. For Chinese students studying abroad, this should be divided into two stages. The first stage is how to learn to accept religious belief from a non-religious person. One of my informants is more open about this:

I don't believe in religion, but they believe in religion, but I don't think I will be surprised if I suddenly believe in religion one day (Yaqi). 
The biggest understanding is not to ignore the conflicts between others and myself, but "I can accept that others are different from me." Even in China, citizens have the right to believe in religion and not to believe in religion, but this established ideological logic has largely affected people in the education system. In other words, we have only learned why we should not believe in religion, but there is no people tell us why we should believe in religion. If religion is a choice, should the two different results be shown? So, when facing the debate about whether to believe in religion, Chinese students do not need to be too sharp. Others are alien to you, and similarly, you are in the eyes of others. The second stage is to learn and understand Islam as a more special existence. The poorer choice is to have bad stereotypes from the beginning. For example, if you think pork is so delicious, why can't they eat pork? Why can't women show their beauty in the public? Why waste time to pray than to spend some time doing something? Why have to fast? Will you get sick when you are hungry? Misunderstandings are due to not understanding, so there is no need to make worthless criticisms. Religion is a kind of spiritual sustenance, and sometimes it can play a good role in calming the soul. Contradictions arise when you think that is a pain, but they are happy.

Religious customs have their own rationality. For example, when the Koran prohibiting people from harming themselves, requiring Muslim women to wear hijab, prohibiting premarital sex and prohibiting abortion, we might as well try to understand its original intention. It is forbidden to do behaviors that hurt oneself, premarital sex and abortion can be seen as a kind of protection of life, although the development of the times is becoming more and more free or not according to people's wishes, such as when abortion faces the unexpected situation of rape, is actually allowed. And I have asked many Muslim women who wear hijabs, they really think that hijabs can protect themselves from infringement to a certain extent. What's interesting is that in women's discourse, many women feel that it's okay not to wear a hijab, and they will not be stigmatized as we imagined. They think wearing a hijab is a choice of their own, "It's better if you wear it, it doesn't matter if you don't wear it." Therefore, we do not need to stand on a moral high ground and use a heroic attitude to think about saving others and interfering with others' choices. My understanding is that "I have the right to wear a hijab" is also a kind of freedom.

In addition to understanding religion correctly, you must also learn to be considerate of the Indonesian's "santai". One trick is not to focus too much on results, but to enjoy the process. I slowly discovered that the biggest difference between the Chinese and Indonesians in doing things may be that the Chinese people are too utilitarian. They have a strong purpose and plan. This is a good thing and to a certain extent it becomes a bad thing. What we are pursuing is to seek efficient methods in a short period of time. In fact, we have put in several times more effort than others. Sometimes it is too tired, which is not conducive to our physical and mental health. The most important point is that when you make the corresponding efforts and fail to achieve the desired result, you will fall into a frustrated situation. 
The essence of understanding lies in empathy. When you put yourself in a position that also needs to be understood by others, you will find that the things you cannot understand are completely unilateral. For example, because of the hot weather in Indonesia, Indonesians are accustomed to take a bath first when they go home, and they think that taking a bath is also an important thing, because they want to make themselves look clean and not smell bad. This is the same reason that Chinese people think that soaking their feet in hot water will help blood circulation. If you are asked and can't be understood why you want to soak your feet in hot water, you will definitely think that because hot water is good for your body, why do they want to ask "why". When we have been doing something or being instilled in a certain kind of thinking since we were young, we will feel that that kind of thinking or behavior is right. Don't subconsciously veto others. If you must need a scientific theoretical basis, you should also consult the information before demonstrating your point of view.

In China, when we were young, we learned to read, studied Chinese ${ }^{5}$ and mathematics, and when grow up, would learn English, physics, chemistry, politics, history and geography. It is worth mentioning that most of our Chinese and literature are learning ancient poems or the works of other celebrities, because this is a classic reading of a country, which like why some Indonesians don't learn science and culture knowledge when they are young, but learn religious etiquette first, because in this country, religious etiquette is set as a prerequisite for ideological values, and the input of this kind of values has been started since childhood. So it has established the importance of religion in the lives of Indonesians, just like ordinary Chinese pursuing money is normal and should be understood.

The inefficiency, slowness, bureaucracy, weak business ability and inflexibility that Chinese international students cannot understand are actually based on our belief that we have stronger abilities than Indonesians. This may have a lot to do with business training exercises. At least when it comes to getting change ${ }^{6}$, the Chinese have the right to speak in the entire world, and it has even become a culture with Chinese characteristics. On the whole, low efficiency, slow work, weak business ability and inflexibility are actually a type of problem. The main source of the problem is the problem of the training system. The existing institutions have not given efficient and flexible training programs. People's behavior is limited to the current field, or lack of an opportunity to inspire innovation or training strategies, which largely affects the Indonesian people's style of doing things. In the final analysis, it is still a matter of habit. Being in this environment for a long time may make people dull or lack the ability to reflect on problems. It is worth mentioning that this so-called "lazy" of treatment does not bother Indonesians too much. It will only be reflected in the face of alien groups. The traditionally created culture does not need to be criticized, and we should accept the "other" culture with a more peaceful heart, rather than the so-called "stupid" and "insensitive".

${ }^{5}$ Chinese, a compulsory subject for Chinese students since childhood.

${ }^{6}$ Chinese people like to round up when they find change. For example, if the cost is 6 yuan, when they pay 10 yuan, they will give 1 yuan more. In this way, you can get the convenience of changing 5 yuan. 


\section{- Enjoy Indonesian style}

In order to ensure a healthy life, I think the first thing that should be solved is the dietary problem. The two solutions to dietary problems are: cook your own meals and find the flavors of Indonesian food that suit you. Let me talk about the first point. The raw materials needed for cooking are recommended to be purchased from supermarkets or markets. If you go to the traditional market early, you can buy cost-effective ingredients, fresh and cheap, as well as meat. However, it is recommended to buy seafood ingredients in supermarkets or shopping malls to ensure relatively high hygiene and safety standards. There are some Chinese-owned shops on Malioboro Street. The familiar spices sold in them can effectively alleviate homesickness. There are supermarkets opened by Chinese in Jakarta, and many items can be purchased online and delivered by express delivery. Indonesia does not have real peppercorns, nor does it have the kind of chili powder commonly found in China. International students who like to eat spicy flavors suggest that bring a little pepper and dried chili powder from China.

The second point is that there are many choices worth trying in Indonesian cuisine. Because the biggest difficulty facing Indonesian cuisine at the beginning is unbearable sweetness. The soup is sweet, the noodles are sweet, and the fried rice is also sweet. There are also sweet tastes in Chinese cuisine, but the sweetness is completely different from that of Indonesian cuisine. Similarly, Chinese students who can't stand the sweet taste can choose to try "penyet", "geprek", Padang cuisine, "capcay", chicken soup and beef soup. Some fried rice can be unsweetened, and which I like very much, fried tofu. You can choose to try sate, chicken noodles, etc. if you can accept the sweetness. All in all, don't be afraid to try. Some foods that seem to be resistant at first are actually really delicious. If you are willing to try, you can skip it next time if you don't like it at most, but if you don't try it, you will miss the opportunity to have a delicacy you like. It is worth mentioning that there are some snacks on the side of the road, those kaki lima snacks may really surprise you sometimes.

In addition to cooking by yourself and getting used to Indonesian cuisine, Yogyakarta actually has authentic Chinese restaurants, such as "Medan lezat" and several good Cantonese restaurants, which can help relieve serious homesickness when there is a strong desire. In addition, there are many choices of Japanese and Korean dishes. For Western cuisine, although many local elements are added, there are also many types. Chinese students can choose their own food according to their preferences.

The hot and humid climate in Yogyakarta is the main reason for the large number of mosquitoes. In order to avoid mosquito bites, bringing mosquito nets from the country is not recommended, because local mosquito coils or insecticides are more effective than mosquito nets. What I would suggest is to bring several sets of bed sheets and quilt cover. The best way to prevent ants and geckos is to keep the room clean. It is best not to put cooked food such as boiled eggs in the room. Although all these years have passed, I still haven't learned not to be afraid of geckos, but learning to "get along " friendly with geckos can help you solve the problem of mosquitoes in the room. 
I also have something to say about finding a satisfactory apartment in the early stages of acculturation. Although every group of Chinese international students will be accompanied and assisted by the tutor when they arrive, if the apartment recommended by them is not satisfied, or when they were forced to move because we touched some taboos in the apartment at the time. In this case, you can only choose to find an apartment yourself. The first preparation is transportation. It's best to have a motorcycle, because even when riding a motorcycle, you have to stop again and again when you find an acquired apartment, check and ask, let alone if you take a taxi through those unknown alleys will cause much trouble. You can also try some application that recommends apartments, such as mami kost. In this way, you can get a preliminary understanding, and then look for it purposefully. It is better than when we were walking street by street when we saw the apartment, we walked in and asked if there were any rooms available. In addition to living in an apartment, if you have the right opportunity, you can also ask a few friends to rent "rumah" . The advantage of "rumah" is that independence and privacy will be stronger. The disadvantage is that you have to buy everything yourself, and if things are broken, you have to fix it yourself. Whether you choose an apartment or a "rumah", in addition to your personal choice, you must also pay attention to whether to provide hot water. The physiques of Chinese and Indonesians are not the same. I have had a fever during the daytime and at night because of cold water bathing. Therefore, for Chinese students with poor physique, I do not recommend taking cold water bathing.

Learn to pay more attention to etiquette and to get rid of bad tempers more effectively, although the informant believes that these etiquettes are shaped by a strict hierarchy:

Their hierarchical concepts are relatively clear and definite. This situation can form a more standardized social order, such as "elderly first". There are also such hierarchical concepts among peers, which well constrain people's behavior (Kai).

To a certain extent, the strict hierarchical system means a kind of alienated relationship, but the degree is often controlled by ourselves. Just like the tradition in the school, it is difficult for us to easily joke with some older and more respected teachers. At first, I think this atmosphere makes me feel very serious, but this is not a level worth writing about etiquette, because even Indonesian students basically respect their teachers, and when facing teachers, they often put themselves in a very low position to show their desire for knowledge. But different teachers will also have some different styles. The focus of school etiquette is not how to learn to keep a low profile like an Indonesian, but to adapt to the different communication styles of each teacher.

In society, the well-being brought about by etiquette is also the kind concern from strangers. Many international students have personal experience and received help from strangers when they encountered difficulties:

I think the distance between them is very close. For example, if you ride a motorcycle and fall down on the road, many people will care about you. This is almost a rare occurrence in China (Yaqi). 
I think what we learn in this environment is not only to accept the help of others, but also to learn to help others with a warm heart. Including the "gotong royong7" that Indonesians often say, maybe just a kind reminder will bring unexpected benefits to others. The benefits of doing so are not only reflected in our acculturation, but can improve individual social participation and let yourself and others not be so indifferent.

Let's talk about the most serious problems that many international students feel faced in the process of acculrating:

Language is also very important. After I went, I would invite different Indonesians out for dinner. I didn't understand them at first, but gradually I understood (Awen).

Many adaptors think that language is the most important point in the process of acculturation, and I generally agree with this point of view. According to my personal experience, the fastest way to improve your language is to talk more. There is no other shortcut, because in your usual communication with Indonesians, you can know their language habits and authentic expressions. My informant also made this suggestion:

To speak Indonesian well, first of all do not speak Chinese. If you are already in Indonesia and you want to integrate into Indonesian culture or environment, you should not speak Chinese (Yanxiu).

I don't recommend taking the dictionary to a cafe to actively talk to Indonesians, because firstly it will slow down the efficiency, and secondly, it may affect the experience of others, unless the person you find also happens to be very idle and has nothing to do, but in general individuals who go to cafes have their own things to do and generally won't refuse you because of their friendliness. A better approach is to quickly find some Indonesian people who are not too far apart in age, and you can get along with them, and establish a close relationship, provided that she/he is also willing to become good friends with you. The advantage of this is that it is more stable than just finding an Indonesian to practice oral language. At the same time, you can also gain a friendship from a different race. Whether in the process of playing together or in conversation, there are more opportunities to get in touch with more Indonesians and their true core culture, because you may be introduced to his other friends and get a richer experience. Of course, this may also be a brave attempt, because when you go out alone with Indonesians, both men and women may be at risk of being deceived or harmed. There is no good way to avoid it. The only thing we can do is to pay more attention to observation, and try to refer to whether the person's character are correct or not bad from his words or behavior.

When the group is more cohesive, the easier it is to lose access to the core local culture. Because when most people of the same ethnic group get together, the more familiar we

\footnotetext{
7 Gotong royong in literal meaning is "mutual assistance". Gotong Royong is seen as an obligation of individual towards society. The idea of Gotong royong is sharing of burdens between the member of community. ... It's a social solidarity in society within smaller bubbles of community.
} 
are with the primitive culture, the more unfamiliar the culture we adapt to. According to my personal experience, creating a lower degree of external isolation is particularly critical. A low degree of cohesion does not mean that you can reduce interactions with friends from your home country. On the contrary, establishing a deep friendship with friends from your home country is an effective way to relieve homesickness. However, the low degree of cohesion can be created by oneself. The development of modern social networks makes it easier for us to meet strangers. Under the premise of ensuring our own safety, I actually feel the hospitality of the people of Yogyakarta. Perhaps because it was 2016, the group of foreign students in Yogyakarta was not as strong as it is now. People's curiosity about foreigners has created better and more convenient social interaction for Chinese students abroad. As long as you have a tolerant and sincere heart, let go of your prejudices and fears, the people of Yogyakarta can really take you to experience a cultural experience that is different from when exploring with the Chinese friends.

If we cannot eliminate stereotypes ideologically and treat ourselves as a local social individual from the habit, then the process of acculturation will become difficult and ineffective. Only when Chinese students truly understand the differences in ideology and values brought about by religion, and gradually start to enjoy a new life, can the above strategies be carried out. And because of the closed state that may be brought about by higher cohesion, we need to create more opportunities to meet and get acquainted with Indonesians.

\section{Conclusion}

What are the main difficulties faced by Chinese students in the process of acculturating? In terms of internal factors, they each have the strengths and weaknesses of individual personalities for acculturation, and the subjectively higher concept of social status determines whether they think they should take the initiative to adapt to the environment or the environment should be changed. In terms of external factors, Chinese students have mainly experienced differences in values and traditional culture. Differences in values are mainly caused by religious differences and traditional thinking; differences in traditional culture include differences in diet, climate, customs, and language. Finally, the high degree of cohesion among the same ethnic group has also become a challenge in the process of positive acculturation.

In chronological order, first of all, improving language skills should be the first preparation. The easiest way to improve and can achieve great progress in the shortest time is oral language ability, which requires Chinese students to continue to communicate with others or listen to others' chat skills. Secondly, adapting to external traditions and customs can give us a less disappointing experience. This includes accepting local behaviors and food, adapting to the hot climate and learning to get used to ants, mosquitoes and living environment. Finally, after accumulating experience in language and daily life, we should have a new head. The transformation of thought is the most difficult and important part. Only when we truly recognize certain "differences" can we really participate in it and enjoy it. In addition, it is also essential to know how 
to use the social capital provided by the school or the tutor to deepen the communication experience. It is best not to "depend on" Chinese friends too much.

\section{Conflicts of Interest:}

The authors declare no conflict of interest.

\section{Acknowledgement:}

Thanks to Department of Anthropology UGM and to informants for providing the important information. Thanks for my experience of living in Indonesia over the past few years.

\section{References}

Anne-Marie Masgoret \& Colleen Ward (2006). Cultrue learning approach of acculturation. Acculturation Psychology. Chapter 5: 58-77.

Christopher Sullivan \& Susan Kashubeck-West (2015). The Interplay of International Students' Acculturative Stress, Social Support, and Acculturation Modes. Journal of International Students. Vol.5, Issue 1 (2015), pp. 1-11.

ChiaChih DC Wang \& Brent Mallinckrodt (2006). Acculturation, Attachment, and Psychosocial Adjustment of Chinese/Taiwanese International Students. Journal of Counseling Psychology. Vol. 53, No. 4, 422-433.

Mohammad Syaroni Syawaludin, Budi Suprapto \& Himawan Sutanto (2020). Selfmanagement Analysis of International University Student in Coping with Culture Shock in Indonesia. MEDIO. Vol 2, No 1, July 2020, pp. 62-84.

Ginda Rahmita Sari \& M. A. Subandi (2015). Akulturasi Psikologis para Self-Initiated Expatriate. GADJAH MADA JOURNAL OF PSYCHOLOGY. VOLUME 1, NO. 1, JANUARI 2015: 13-29. ISSN: 2407-7798

Junqian Ma (2017). Cooperative Activity as Mediation in the Social Adjustment of Chinese International Students. Journal of International Students. Volume 7, Issue 3 (2017), pp. 856-875. http://jistudents.org/. doi: 10.5281/zenodo.570038.

Alfred Presbitero (2016). Culture shock and reverse culture shock: The moderating role of cultural intelligence in international students' adaptation. International Journal of Intercultural Relations. 53(2016)28-38.

Omar Moufakkir (2013). Culture shock, what culture shock? Conceptualizing culture unrest in intercultural tourism and assessing its effect on tourists'perceptions and travel propensity. Tourist Studies. 13(3)322-340.

Oberg K (1960). Cultural shock: Adjusment to New Cultural Environments. Practical Anthropology 7: 177-182. 